\title{
Long-term clinical outcomes in cirrhotic chronic hepatitis B patients treated with tenofovir disoproxil fumarate for up to 5 years
}

\author{
Maria Buti $\cdot$ Scott Fung $\cdot$ Edward Gane $\cdot$ Nezam H. Afdhal $\cdot$ \\ Robert Flisiak $\cdot$ Selim Gurel $\cdot$ John F. Flaherty $\cdot$ Eduardo B. Martins • \\ Leland J. Yee · Phillip Dinh · Jeffrey D. Bornstein • G. Mani Subramanian • \\ Harry L. A. Janssen · Jacob George $\cdot$ Patrick Marcellin
}

Received: 12 July 2014/ Accepted: 17 February 2015/Published online: 13 March 2015

(C) The Author(s) 2015. This article is published with open access at Springerlink.com

\begin{abstract}
Background Phase 3 clinical studies have shown that long-term treatment with tenofovir disoproxil fumarate (TDF) can suppress hepatitis B viral load and promote significant fibrosis regression and cirrhosis reversal in a majority of treated chronic hepatitis B (CHB) patients. This retrospective analysis investigated the impact of baseline cirrhosis status on virologic, serologic, and histologic outcomes in patients treated with TDF.

Methods Patients enrolled in studies GS-US-174-0102 and GS-US-174-0103 who had baseline liver biopsy-diagnosed cirrhosis and entered the open-label phase of the
\end{abstract}

\section{Buti $(\bowtie)$}

Servei de Medicina Interna-Hepatologia, Hospital General Universitari Vall d'Hebron, Pg. Vall d'Hebron, 119-129,

08035 Barcelona, Spain

e-mail: mbuti@vhebron.net

S. Fung

Department of Medicine, Toronto General Hospital, University of Toronto, 200 Elizabeth Street, Toronto, ON M5G 2C4,

Canada

e-mail: scott.fung@unh.ca

\section{E. Gane}

Department of Gastroenterology and Hepatology, Auckland City

Hospital, 2 Park Road, Auckland 1142, New Zealand

e-mail: EdGane@adhb.govt.nz

\section{N. H. Afdhal}

Department of Hepatology, Beth Israel Deaconess Medical

Center, 330 Brookline Avenue, Boston, MA 02215, USA

e-mail: nafdhal@bidmc.harvard.edu

R. Flisiak

Department of Infectious Diseases and Hepatology, Medical

University of Białystok, 15-540 Białystok, Poland

e-mail: robert.flisiak@umb.edu.pl studies were included in the virologic and serologic analyses. Patients (both $\mathrm{HBeAg}$ positive and negative) with paired liver biopsies at baseline and 5 years $(N=348)$ were included in a histologic analysis.

Results After 5 years on study, comparing patients with and without baseline cirrhosis, respectively: 99.2 and 98.0\% achieved virologic response (hepatitis B viral load $<69 \mathrm{IU} / \mathrm{ml})(p=0.686) ; 79.7$ and $81.9 \%$ had normal serum levels of alanine aminotransferase $(p=0.586)$; 4.0 and $1.2 \%$ developed hepatocellular carcinoma $(p=0.044)$. In HBeAg-positive patients with and without baseline cirrhosis, HBsAg loss occurred in 14.4 and $8.3 \%$

\section{S. Gurel}

Department of Gastroenterology, University of Uludag, Özlüce Mh., 16120, Bursa 16059, Turkey

e-mail: gurels@uludag.edu.tr

J. F. Flaherty - E. B. Martins - L. J. Yee · P. Dinh .

J. D. Bornstein - G. Mani Subramanian

Gilead Sciences, Inc., 333 Lakeside Drive, Foster City,

CA 94404, USA

e-mail: John.Flaherty@gilead.com

E. B. Martins

e-mail: Eduardo.Martins@gilead.com

L. J. Yee

e-mail: Leland.Yee@gilead.com

P. Dinh

e-mail: Phillip.Dinh@gilead.com

J. D. Bornstein

e-mail: Jeffrey.Bornstein@gilead.com

G. Mani Subramanian

e-mail: Mani.Subramanian@gilead.com 
of patients, respectively ( $p=0.188$ ). One HBeAg-negative patient had HBsAg loss.

Conclusions This represents the largest analyses to date of CHB patients with sequential liver biopsies demonstrating that treatment with TDF for up to 5 years is associated with favorable virologic, serologic, and histologic outcomes, regardless of baseline cirrhosis status. Notably, histologic improvement was observed in the majority of cirrhotic and noncirrhotic patients.

Keywords Antiviral agent - Chronic hepatitis B . Cirrhosis - Hepatitis B e antigen - Hepatitis B surface antigen $\cdot$ Tenofovir disoproxil

\section{Background}

It is estimated that up to $40 \%$ of patients with chronic hepatitis $\mathrm{B}(\mathrm{CHB})$ will progress to cirrhosis, liver failure, or hepatocellular carcinoma (HCC) [1]. In fact, hepatitis B infection may account for $30 \%$ of cirrhosis cases and $50 \%$ of HCC cases worldwide [2]. Because high serum hepatitis B virus (HBV) DNA levels are associated with increased risk of developing cirrhosis and HCC [3, 4], intervening with highly potent antiviral agents may alter the clinical course and prevent the development of these adverse liver-related outcomes $[2,5]$. There are limited data regarding the impact of long-term antiviral therapy on clinical outcomes in cirrhotic CHB patients. However, over the past decade, studies of oral nucleot(s)ide analogs have suggested that reducing HBV viral load may prevent disease progression in CHB patients and, in a small patient series, reverse preexisting cirrhosis [6-9].

Published results from a combined cohort of two ongoing phase 3 studies of tenofovir disoproxil fumarate (TDF) in CHB patients $(N=641)$ have provided evidence that long-term HBV suppression can promote significant

\footnotetext{
H. L. A. Janssen

Division of Gastroenterology, Erasmus MC University Hospital, Rotterdam, The Netherlands

e-mail: harry.janssen@uhn.ca

J. George

Storr Liver Unit, Westmead Millennium Institute, Westmead Hospital, University of Sydney, Hawkesbury Road, Westmead, NSW 2145, Australia

e-mail: jacob.george@sydney.edu.au

P. Marcellin

Service d'Hépatologie, Viral Hepatitis Research Centre, Hôpital Beaujon, 100 Boulevard du General Leclerc, 92110 Clichy, France

e-mail: patrick.marcellin@bjn.aphp.fr
}

fibrosis regression and cirrhosis reversal in the majority of treated patients [10]. Of the 348 patients with paired liver biopsies at baseline and year 5, $87 \%$ experienced histologic improvement (defined as a $\geq 2$-point reduction in the Knodell necroinflammatory score without worsening of fibrosis) and $51 \%$ experienced fibrosis regression [10]. Furthermore, $74 \%$ of the 96 patients with baseline cirrhosis exhibited reversal of cirrhosis at year 5 [10]. Of these patients, all but one had Ishak fibrosis scores improved by $\geq 2$ units, and $58 \%$ had fibrosis scores improved by $\geq 3$ units. Twenty-four ( $25 \%$ ) patients had no change in liver fibrosis. One $(1 \%)$ patient had worsening of fibrosis from baseline to year 5 (Ishak fibrosis score increase from 5 to 6 ). The question remains, however, whether long-term outcomes in CHB patients treated with TDF are influenced by patients' baseline cirrhosis status. In this subanalysis of the two phase 3 studies, we report long-term clinical, virologic, serologic, and histologic outcomes in patients with and without baseline cirrhosis.

\section{Methods}

Study design

This retrospective pooled analysis investigates clinical, serologic, and histologic outcomes in a subset of CHB patients who had liver biopsy at baseline and year 5. These patients were initially treated for 1 year (48 weeks) with either adefovir dipivoxil (ADV) or TDF in two randomized, controlled phase 3 studies [GS-US-174-0102 (study 102) and GS-US-174-0103 (Study 103)] before continuing to openlabel TDF for a planned additional 9 years. The studies are registered with ClinicalTrials.gov (NCT00117676 and NCT00116805, respectively). Six hundred forty-one patients were initially randomized; of these, 634 had liver biopsy data available at baseline. Complete medical history and full physical examination were done at baseline. Key exclusion criteria were coinfection with HIV-1, or hepatitis $\mathrm{C}$ or D virus, evidence of $\mathrm{HCC}$, a creatinine clearance $<70 \mathrm{ml} / \mathrm{min}$, a hemoglobin level $<8 \mathrm{~g} / \mathrm{dl}$, a neutrophil count $<1,000 / \mathrm{mm}^{3}$, and liver decompensation or failure. Decompensated liver disease was defined as conjugated bilirubin $>1.5 \times$ the upper limit of normal (ULN), prothrombin time $>1.5 \times$ ULN, platelet count $<75,000 / \mathrm{mm}^{3}$, serum albumin $<3.0 \mathrm{~g} / \mathrm{dl}$, or prior history of hepatic decompensation (e.g., ascites, jaundice, encephalopathy, variceal hemorrhage). Detailed descriptions of the study populations, design, and methods have been reported previously [10-12] (Fig. 1a).

Demographic, baseline, and on-treatment characteristics of patients who had cirrhosis (Ishak fibrosis score $\geq 5$ ) at baseline were compared with patients who did not have cirrhosis (Ishak fibrosis score $\leq 4$ ) at baseline [13]. 
Fig. 1 Study design and patient disposition. a The designs of the two phase- 3 randomized double-blind placebo-controlled studies have been described previously [10-12]. Briefly, 641 patients with chronic HBV infection were randomized to tenofovir disoproxil fumarate (TDF) $300 \mathrm{mg}$ daily $(n=426)$ or adefovir dipivoxil (ADV) $10 \mathrm{mg}$ daily $(n=215)$ for 1 year. Afterward, patients were eligible to receive TDF $300 \mathrm{mg}$ daily in an open-label extension study for up to 9 additional years. Mandatory liver biopsies were obtained at baseline and 1 year. A third, optional biopsy was obtained at year 5. b Of 641 patients randomized, 634 had liver biopsy data available at baseline. Of these 634,152 were classified as having cirrhosis and 482 as having no cirrhosis. $\mathrm{HBeAg}$ - hepatitis B e antigen negative, $H B s A g+$ hepatitis $\mathrm{B}$ surface antigen positive, $H B V$ hepatitis B virus

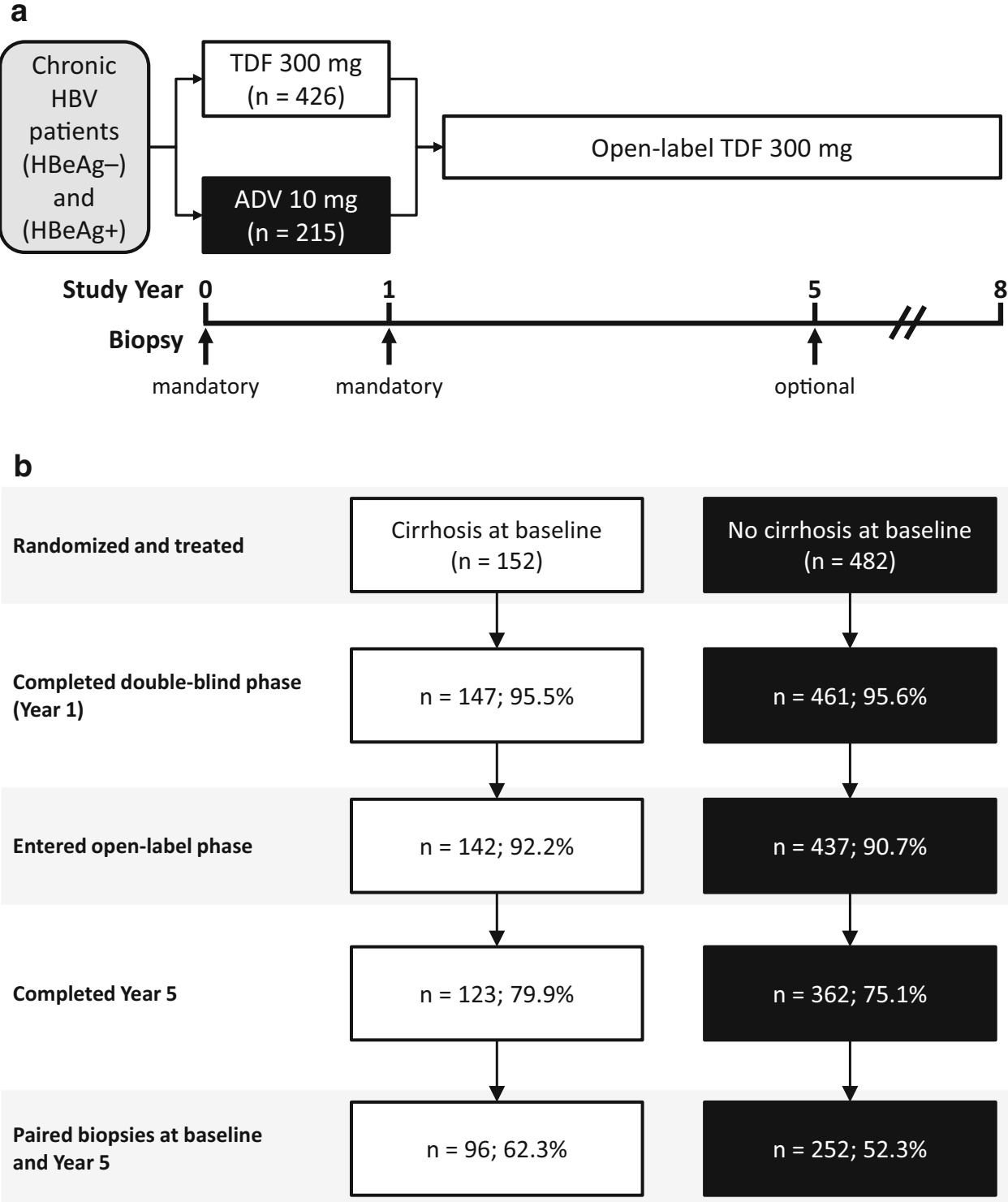

Measures of biochemical response included the proportion of patients with normal serum levels of alanine aminotransferase (ALT) and the proportion of patients with abnormal ALT levels at baseline who achieved ALT normalization (at or below the upper limit of normal (ULN), which was $34 \mathrm{IU} / \mathrm{ml}$ for females and $43 \mathrm{IU} / \mathrm{ml}$ for males). Serologic end points included serum hepatitis $B$ surface antigen (HBsAg) loss and serum hepatitis B e antigen ( $\mathrm{HBeAg}$ ) loss. Virologic response was defined as the proportion of patients with plasma HBV DNA $<69$ IU/ ml. The proportion of patients with plasma HBV DNA $<29 \mathrm{IU} / \mathrm{ml}$, the lower limit of quantification of the COBAS TaqMan assay, was also analyzed [10].

Patients who had paired liver biopsies at baseline and at year 5 were evaluated for histologic changes. The changes from baseline in Knodell necroinflammatory and Ishak fibrosis scores were compared between patients with and without cirrhosis. The procedure for evaluating liver biopsies has been previously described [10]. Regression of fibrosis was defined as $a \geq 1$-point decline in the Ishak fibrosis score [10, 13].

Statistical analyses

Descriptive statistics (mean and standard deviation for continuous variables, frequency and percentage for categorical variables) was used to summarize baseline demographics and disease characteristics for patients with and without baseline cirrhosis. Outcome measures at year 5 were summarized similarly using an on-treatment analysis, whereby all patients on study with non-missing data were analyzed. The Wilcoxon rank-sum test and Fisher's exact 
test were used to compare continuous and categorical variables, respectively. Proportions of patients with HBsAg loss were estimated using the Kaplan-Meier method; comparison between groups was done via log rank test. Histologic improvements (Ishak fibrosis stage and Knodell necroinflammatory score) were compared using Fisher's exact test on on-treatment data.

\section{Results}

A total of 641 patients were randomized in the two phase-3 clinical trials (Fig. 1a). Of the original cohort, $91.3 \%$ of patients $(n=585)$ entered the open-label phase, and $76.3 \%(n=489)$ completed 5 years of treatment.
Baseline patient and disease characteristics

Baseline biopsies were obtained in 634 of 641 patients; of these, $152(24.0 \%)$ had cirrhosis at baseline and 482 $(76.0 \%)$ did not (Fig. 1b). Of the patients with baseline biopsies, $348(54.9 \%)$ also had biopsies at year 5 [10]. Biopsies were not performed in 141 patients at year 5, primarily because patients refused the procedure. Baseline characteristics of patients with and without cirrhosis are described below and summarized in Table 1. Of the patients with baseline cirrhosis, none were Child-Pugh B or C, none had a history of a decompensating event (e.g., hepatic encephalopathy, ascites), and none had two or more of the following laboratory abnormalities: INR $\geq 1.7$, total bilirubin $\geq 2 \mathrm{mg} / \mathrm{dl}$, or albumin $\leq 3.5 \mathrm{~g} / \mathrm{dl}$.

Table 1 Baseline demographic and disease characteristics

\begin{tabular}{|c|c|c|c|}
\hline Factor & $\begin{array}{l}\text { Cirrhosis at baseline } \\
(n=152)\end{array}$ & $\begin{array}{l}\text { No cirrhosis at } \\
\text { baseline }(n=482)\end{array}$ & $p$ value \\
\hline Patients $>40$ years of age $[n(\%)]$ & $104(68.4)$ & $218(45.2)$ & $<0.001$ \\
\hline Male $[n(\%)]$ & $123(80.9)$ & 345 (71.6) & 0.026 \\
\hline Mean $(\mathrm{SD}) \mathrm{BMI}\left(\mathrm{kg} / \mathrm{m}^{2}\right)$ & $n=15126.5(4.6)$ & $n=47925.1(4.7)$ & $<0.001$ \\
\hline Asian $[n(\%)]$ & $39(25.7)$ & $148(30.7)$ & 0.262 \\
\hline Genotype $[n(\%)]$ & & & 0.043 \\
\hline A & $34(22.4)$ & $67(13.9)$ & \\
\hline B & $10(6.6)$ & $64(13.3)$ & \\
\hline $\mathrm{C}$ & $27(17.8)$ & $83(17.2)$ & \\
\hline $\mathrm{D}$ & $73(48.0)$ & $239(49.6)$ & \\
\hline Other $^{\mathrm{a}}$ & $8(5.3)$ & $29(6.0)$ & \\
\hline HBeAg positive $[n(\%)]$ & $60(39.5)$ & $199(41.3)$ & 0.706 \\
\hline Previous lamivudine experience $>12$ weeks $[n(\%)]$ & $20(13.2)$ & $55(11.4)$ & 0.566 \\
\hline Previous interferon experience $[n(\%)]$ & $27(17.8)$ & $79(16.4)$ & 0.709 \\
\hline Mean (SD) HBV DNA $\left(\log _{10} \mathrm{IU} / \mathrm{ml}\right)$ & $6.8(1.43)$ & $6.9(1.51)$ & 0.288 \\
\hline Mean (SD) HBsAg $\left(\log _{10} \mathrm{IU} / \mathrm{ml}\right)$ & $3.9(0.7)$ & $4.1(0.7)$ & 0.017 \\
\hline Mean (SD) albumin (g/dl) & $4.0(0.4)$ & $4.2(0.3)$ & $<0.001$ \\
\hline Mean (SD) platelet count (cells $/ \mu \mathrm{l})$ & $178,200(50,350)$ & $218,600(54,460)$ & $<0.001$ \\
\hline Mean (SD) Knodell necroinflammatory score & $9(1.6)$ & $8(2.4)$ & $<0.001$ \\
\hline Ishak fibrosis stage $[n(\%)]$ & & & $<0.001$ \\
\hline 0 & 0 & $1(0.2)$ & \\
\hline 1 & 0 & $20(4.1)$ & \\
\hline 2 & 0 & $248(51.5)$ & \\
\hline 3 & 0 & $153(31.7)$ & \\
\hline 4 & 0 & $60(12.4)$ & \\
\hline 5 & $29(19.1)$ & 0 & \\
\hline 6 & $123(80.9)$ & 0 & \\
\hline Patients with normal ${ }^{\mathrm{b}}$ serum ALT levels $[n(\%)]$ & $9(5.9)$ & $18(3.7)$ & 0.252 \\
\hline
\end{tabular}

$A L T$ alanine aminotransferase, $B M I$ body mass index, $H B e A g$ hepatitis B e antigen, $H B s A g$ hepatitis B surface antigen, $H B V$ hepatitis B virus, $S D$ standard deviation

" The "other" category includes patients with genotypes E, F, G, and $\mathrm{H}$ and patients with no genotype information available

b The upper limit of the normal range (ULN) for ALT was $34 \mathrm{IU} / \mathrm{ml}$ for females and $43 \mathrm{IU} / \mathrm{ml}$ for males 


\section{Demographics}

Statistically significant differences in age, sex, and body mass index (BMI) were observed at baseline between patients with and without cirrhosis. Patients with cirrhosis were more likely to be older than 40 years (68.4 vs. $45.2 \%, p<0.001)$ and male (80.9 vs. $71.6 \%, p=0.026)$ and to have a higher BMI $(26.5 \pm 4.6$ vs. $25.1 \pm 4.7 \mathrm{~kg} /$ $\left.\mathrm{m}^{2}, p<0.001\right)$. Racial composition of both cohorts was similar; $25.7 \%$ of patients with cirrhosis and $30.7 \%$ of patients without cirrhosis were of Asian ancestry $(p=0.262)$.

\section{Virologic and serologic characteristics}

At baseline, genotype $\mathrm{D}$ was the predominant $\mathrm{HBV}$ genotype, detected in $48.0 \%$ of patients with cirrhosis and $49.6 \%$ of patients without cirrhosis. The cohort with cirrhosis had a higher proportion of patients with genotype A (22.4 vs. $13.9 \%)$ and a lower proportion of patients with genotype B (6.6 vs. $13.3 \%)$ than the cohort without cirrhosis $(p=0.043$ for distribution of genotypes between cohorts). Mean levels of HBV DNA at baseline were similar between the groups. Patients with cirrhosis had lower mean quantitative HBsAg levels at baseline than patients without cirrhosis. There was no statistical difference in the percentage of patients with positive HBeAg status at baseline between cohorts with and without baseline cirrhosis (39.5 vs. $41.3 \%, p=0.706$ ).

\section{Clinical characteristics}

Similar proportions of patients in both cohorts had normal serum ALT levels at baseline. Patients with baseline cirrhosis were more likely to have lower levels of serum albumin $(p<0.001)$ and lower platelet counts $(p<0.001)$ than patients who had no cirrhosis at baseline. Per protocol, all patients had compensated liver function at baseline.

\section{On-treatment factors}

On-treatment factors for both patient groups are described below and summarized in Table 2 .

\section{Virologic and serologic characteristics}

After 5 years on study, nearly all patients in both cohorts achieved and maintained a virologic response, regardless of baseline cirrhosis status. At year 5, $99.2 \%$ of the cohort with cirrhosis and $98.0 \%$ of the cohort without cirrhosis had HBV DNA $<69 \mathrm{IU} / \mathrm{ml}(p=0.686)$; $99.2 \%$ of the cohort with cirrhosis and $97.4 \%$ of the cohort without cirrhosis had HBV DNA $<29 \mathrm{IU} / \mathrm{ml}(p=0.465)$. No patient in either cohort had persistent viremia, defined as never having had undetectable HBV DNA. Moreover, during year 5, only 4 of 495 patients experienced virologic breakthrough, 3 of whom had documented non-adherence to TDF.

Of the patients who were $\mathrm{HBeAg}$ positive at baseline, 61.9 and $45.4 \%$ of patients with and without baseline cirrhosis, respectively, experienced $\mathrm{HBeAg}$ loss $(p=$ 0.075 ) by year 5 . Both cohorts demonstrated an early decline in circulating HBsAg; however, despite having a higher mean baseline HBsAg level, the mean change in HBsAg level at week 12 in the cohort without cirrhosis was greater than in the cohort with cirrhosis $(p=0.037)$. By year 5, HBsAg loss in the HBeAg-positive cohort occurred in 14.4 and $8.3 \%$ of patients with and without cirrhosis, respectively ( $p=0.188$; on-treatment analysis; KaplanMeier estimate). Only one HBeAg-negative patient had HBsAg loss.

\section{Clinical characteristics}

The majority of patients achieved a biochemical response; 79.7 and $81.9 \%$ of patients with and without baseline cirrhosis, respectively, had normal ALT levels $(p=0.586)$ at year 5. Greater increases in platelets (30,700 vs. 20,100 cells $/ \mu \mathrm{l} ; p=0.030)$ and serum albumin $(0.3$ vs. $0.1 \mathrm{~g} / \mathrm{dl}$; $p<0.001)$ occurred in the cohort with cirrhosis, but both cohorts experienced significant improvements in these two parameters by year 5 on study. There were no episodes of liver decompensation, such as ascites or variceal bleeding, or liver failure observed in the two studies. Few patients in either cohort developed HCC at 5 years [cirrhotics: $4.0 \%$ $(n=6)$ vs. noncirrhotics: $1.2 \%(n=6) ; p=0.044]$. At the time of this analysis, of the 12 patients who had been diagnosed with HCC, 3 died as a result of their disease, 4 with early-stage HCC achieved disease resolution via surgery or radiofrequency ablation, and 5 continued to have unresolved HCC [10].

\section{Histologic characteristics}

The 5-year liver biopsy was obtained in 96 (63.2\%) of 152 patients with baseline cirrhosis and $252(52.3 \%)$ of 482 patients without cirrhosis. Among these, $93.8 \%$ of patients with cirrhosis achieved an improvement in the Knodell necroinflammatory score of $\geq 1$ unit compared with $90.5 \%$ of patients without cirrhosis ( $p=0.746$ ) (Fig. 2). Only two $(0.8 \%)$ patients, both initially without cirrhosis, experienced a worsening of the Knodell necroinflammatory score. All other patients had no change in the necroinflammatory score. 
Table 2 Clinical outcomes at 5 years, by baseline cirrhosis status (on-treatment analysis)

\begin{tabular}{|c|c|c|c|}
\hline Factor & $\begin{array}{l}\text { Cirrhosis at baseline } \\
(n=152)\end{array}$ & $\begin{array}{l}\text { No cirrhosis at } \\
\text { baseline }(n=482)\end{array}$ & $p$ value \\
\hline HBV DNA <69 IU/ml [n/N (\%)] & $119 / 120(99.2)$ & $339 / 346(98.0)$ & 0.686 \\
\hline HBV DNA <29 IU/ml [n/N (\%)] & $119 / 120(99.2)$ & $337 / 346(97.4)$ & 0.465 \\
\hline Normal ALT level $[n / N(\%)]$ & $94 / 118(79.7)$ & 286/349 (81.9) & 0.586 \\
\hline Normalized ALT level $[n / N(\%)]$ & $85 / 109(78.0)$ & $271 / 333(81.4)$ & 0.486 \\
\hline HBsAg loss ${ }^{\mathrm{a}, \mathrm{b}}(\%)$ & 14.4 & 8.3 & 0.188 \\
\hline $\begin{array}{l}\text { Mean (SD) change in HBsAg from baseline } \\
\text { to week } 12\left(\log _{10} \mathrm{IU} / \mathrm{ml}\right)\end{array}$ & $\begin{array}{l}n=149 \\
-0.1(0.5)\end{array}$ & $\begin{array}{l}n=470 \\
-0.2(0.4)\end{array}$ & 0.037 \\
\hline $\operatorname{HBeAg} \operatorname{loss}^{\mathrm{a}}[n / N(\%)]$ & $26 / 42(61.9)$ & $54 / 119(45.4)$ & 0.075 \\
\hline Mean (SD) change in platelets (cells/ $\mu 1)$ & $\begin{array}{l}n=117 \\
30,700(43,930)\end{array}$ & $\begin{array}{l}n=343 \\
20,100(40,150)\end{array}$ & 0.030 \\
\hline Mean $(\mathrm{SD})$ change in albumin $(\mathrm{g} / \mathrm{dl})$ & $\begin{array}{l}n=119 \\
0.3(0.4)\end{array}$ & $\begin{array}{l}n=353 \\
0.1(0.3)\end{array}$ & $<0.001$ \\
\hline Development of HCC $[n / N(\%)]$ & $6 / 152(4.0)$ & $6 / 482(1.2)$ & 0.044 \\
\hline
\end{tabular}

No patients in either group developed hepatic encephalopathy or variceal bleeding; one patient without cirrhosis at baseline developed ascites (in association with HCC)

$A L T$ alanine aminotransferase, $H B e A g$ hepatitis B e antigen, $H B s A g$ hepatitis B surface antigen, $H B V$ hepatitis B virus, $H C C$ hepatocellular carcinoma, $S D$ standard deviation

${ }^{a} \mathrm{HBeAg}$-positive patients only

b Kaplan-Meier estimated proportion

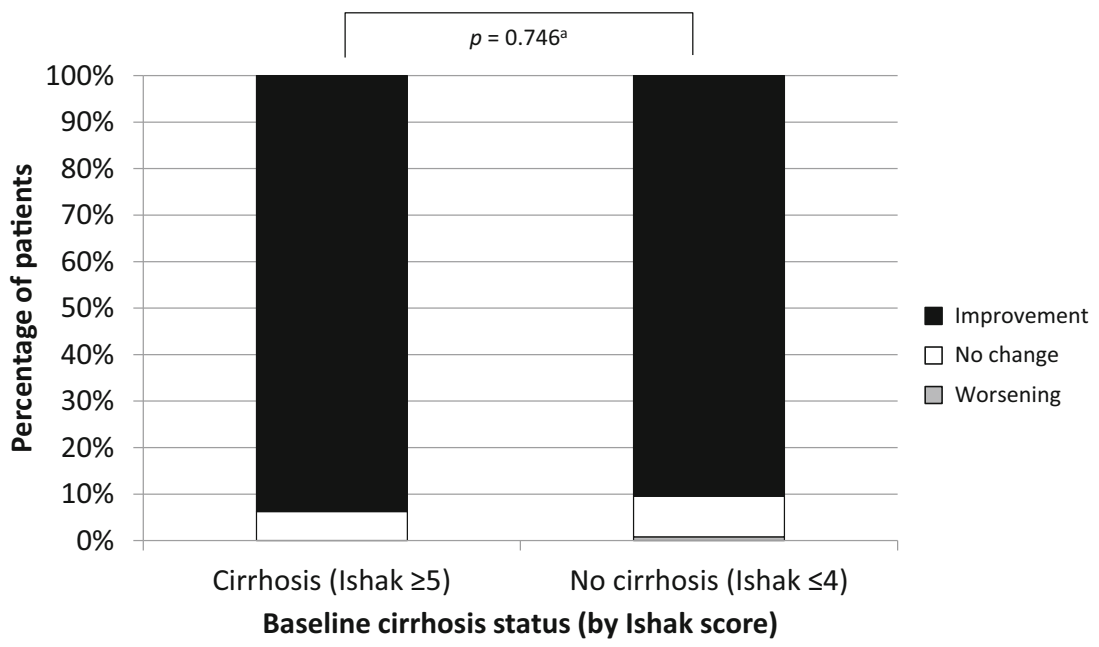

Fig. 2 Histologic changes at year 5 among patients with and without baseline cirrhosis. Among 348 patients with paired biopsies at year 5 of treatment, 96 had baseline cirrhosis and 252 had no baseline cirrhosis. ${ }^{a} p$ value calculated using Fisher's exact test. Necroinflammatory response (Knodell scores) at year 5. Ninety-four percent of

\section{Safety}

A summary of adverse events reported in patients with and without baseline cirrhosis through year 5 is provided in Table 3. There were no statistically significant differences between the two cohorts in key safety parameters. The incidences of renal adverse events in the cohort with and patients in the cohort with baseline cirrhosis and $91 \%$ in the cohort with no baseline cirrhosis experienced improvement in the Knodell necroinflammatory score. Improvement was defined as a decrease in score of $\geq 1$ unit; worsening was defined as an increase in score of $\geq 1$ unit

without baseline cirrhosis, as determined by an increase in serum creatinine $>0.5 \mathrm{mg} / \mathrm{dl}$ above baseline $(1.4 \mathrm{vs}$. $0.7 \%$ ), phosphorus levels $<2.0 \mathrm{mg} / \mathrm{dl}$ ( 1.4 vs. $0.9 \%$ ), and creatinine clearance $<50 \mathrm{ml} / \mathrm{min}(0.7$ vs. $0.0 \%)$, were all low. The single patient with baseline cirrhosis who experienced on-study creatinine clearance $<50 \mathrm{ml} / \mathrm{min}$ had long-standing, medically managed hypertension, was 
Table 3 Safety summary during the open-label phase

\begin{tabular}{lcc}
\hline Parameter $[n(\%)]$ & $\begin{array}{l}\text { Cirrhosis at baseline } \\
(n=142)\end{array}$ & $\begin{array}{l}\text { No cirrhosis at } \\
\text { baseline }(n=437)\end{array}$ \\
\hline Patients with TEAE & $122(85.9)$ & $358(81.9)$ \\
Patients with TESAE & $29(20.4)$ & $59(13.5)$ \\
Patients with TEAE leading to study drug discontinuation & $1(0.7)$ & $7(1.6)$ \\
Patients with treatment-emergent grade $3 / 4$ AE & $21(14.8)$ & $56(12.8)$ \\
Increase in serum creatinine of $\geq 0.5 \mathrm{mg} / \mathrm{dl} \mathrm{from} \mathrm{baseline}{ }^{\mathrm{a}}$ & $2(1.4)$ & $3(0.7)$ \\
Serum phosphorus $<2.0 \mathrm{mg} / \mathrm{dl}^{\mathrm{a}}$ & $2(1.4)$ & $4(0.9)$ \\
Creatinine clearance $<50 \mathrm{ml} / \mathrm{min}^{\mathrm{a}, \mathrm{b}}$ & $1(0.7)$ & 0 \\
\hline
\end{tabular}

The analysis set includes only patients who entered the open-label phase

$A E$ adverse event, TEAE treatment-emergent adverse event, TESAE treatment-emergent serious adverse event

${ }^{\text {a }}$ Each parameter was confirmed on retest

${ }^{\mathrm{b}}$ By the Cockcroft-Gault equation

$>50$ years of age, and was prescribed nonsteroidal antiinflammatory medications as needed.

\section{Discussion}

Historically, CHB patients with cirrhosis have poorer prognosis, including greater risk for the development of HCC, than their CHB counterparts without cirrhosis [14, 15]. Our analyses suggest that, for the most part, long-term TDF treatment in CHB patients can lead to similar outcomes in patients with or without baseline cirrhosis. The exception is for HCC development, where our analyses revealed a significantly higher rate of HCC development in patients with baseline cirrhosis than without (4.0 vs. $1.2 \%$, $p=0.044)$. Nevertheless, the overall incidence of HCC development in either cohort was low. Rates of virologic response observed in our current analyses were similar between cohorts, suggesting that at year 5 in our studies, at least, the presence of cirrhosis at baseline may contribute more to the development of HCC during the study timeframe than viral load on therapy does. Therefore, surveillance for HCC should be performed regardless of $\mathrm{HBV}$ DNA suppression.

It has been demonstrated that decompensated cirrhosis is associated with poorer outcomes [16]. Moreover, HBV DNA suppression has been shown to prevent progression of clinical disease [8]. Because the two clinical studies excluded patients with decompensated liver disease, our analyses cannot address the effect of TDF on the clinical course of decompensated patients. However, over 5 years, there were no cases of hepatic decompensation in either study, an encouraging observation given the $2.7 \%$ annual rate of liver decompensation previously observed in $\mathrm{CHB}$ patients [17].

In our analyses, patients without cirrhosis were more likely to experience early $\mathrm{HBsAg}$ declines of greater magnitude. This observation might be related to the significantly higher level of HBsAg that noncirrhotic patients had at baseline, a pattern that has been reported before [18]. A detailed report on the kinetics of HBsAg decline and loss in studies 102 and 103 was recently published, confirming a significant correlation between early decline and loss of HBsAg [19].

The generalizability of our findings to patients with cirrhosis may be limited to those with compensated disease given the patient population enrolled under the studies. In addition, the analyses reported were retrospective and therefore subject to the limitations inherent to retrospective analyses.

Through 5 years of treatment, no significant differences were observed between the two cohorts in the incidence of treatment-emergent adverse events. Importantly, the occurrence of renal adverse events was low in both cohorts. In summary, our analyses provide evidence that treatment with TDF up to 5 years is equally efficacious and safe in patients with $\mathrm{CHB}$, regardless of whether patients with $\mathrm{CHB}$ are noncirrhotic or have well-compensated cirrhosis at baseline.

Acknowledgements This study was supported by Gilead Sciences, Inc. The authors thank Anna Lau, PhD, of Percolation Communications LLC for medical editorial support, funded by Gilead Sciences, Inc. JG is supported by the Robert W. Storr bequest to the Sydney Medical Foundation, University of Sydney; a National Health and Medical Research Council of Australia (NHMRC) Program Grant no. 1053206, and the Sydney West Translational Cancer Research Centre Partner Program funded by the Cancer Institute NSW.

Compliance with ethical requirements and Conflict of interest Maria Buti declares advisory board/speaker relationships with Gilead, Bristol-Myers-Squibb, and Novartis. Edward Gane declares advisory/speaker relationships with Gilead, Achillion, Merck, Idenix, Novira, and Novartis. Nezam Afdhal has no conflict of interest to declare. Robert Flisiak declares consultancy with and honoraria from AbbVie, Bristol-Myers Squibb, Gilead, Janssen, Merck, Novartis, and Roche as well as research support from Gilead, Janssen, and Roche. 
Selim Gurel declares consultancy with and honoraria from AbbVie, Bristol-Myers Squibb, Gilead, Janssen, Merck Sharp \& Dohme, Roche, and Novartis. John Flaherty, Eduardo Martins, Phillip Dinh, and Mani Subramanian declare employment and stock ownership with Gilead Sciences. Leland Yee and Jeffrey Bornstein declare employment with Gilead Sciences. Harry Janssen declares consultancy with and research support from Bristol-Myers Squibb, Gilead, Innogenetics, Merck, Novartis, and Roche. Jacob George declares consultancy with and honoraria from Roche, Merck Sharp \& Dohme, AbbVie, Gilead, Norgine, Abbott, and Janssen. Patrick Marcellin declares grant, investigator, speaker, and/or consultant relationships with Roche, Gilead, Bristol-Myers-Squibb, Vertex, Novartis, Janssen, Merck Sharp \& Dohme, Boehringer, AbbVie, Pfizer, Alios Biopharma, Idenix, and Akron. Scott Fung and Nezam Afdhal have no conflict of interest to declare.

Informed consent in studies with human subjects All procedures followed were in accordance with the ethical standards of the responsible committee on human experimentation (institutional and national) and with the Helsinki Declaration of 1975, as revised in 2008. Informed consent was obtained from all patients for being included in the study.

Open Access This article is distributed under the terms of the Creative Commons Attribution License which permits any use, distribution, and reproduction in any medium, provided the original author(s) and the source are credited.

\section{References}

1. Lok AS. Chronic hepatitis B. N Engl J Med 2002;346:1682-1683

2. Brown A, Goodman Z. Hepatitis B-associated fibrosis and fibrosis/cirrhosis regression with nucleoside and nucleotide analogs. Expert Rev Gastroenterol Hepatol 2012;6:187-198

3. Chen CJ, Yang HI, Su J, Jen CL, You SL, Lu SN et al. Risk of hepatocellular carcinoma across a biological gradient of serum hepatitis B virus DNA level. JAMA 2006;295:65-73

4. Iloeje UH, Yang HI, Su J, Jen CL, You SL, Chen CJ. Predicting cirrhosis risk based on the level of circulating hepatitis B viral load. Gastroenterology 2006;130:678-686

5. Lok AS, McMahon BJ. Chronic hepatitis B: update 2009. Hepatology 2009;50:661-662

6. Dienstag JL, Goldin RD, Heathcote EJ, Hann HW, Woessner M, Stephenson SL et al. Histological outcome during long-term lamivudine therapy. Gastroenterology 2003;124:105-117

7. Hadziyannis SJ, Tassopoulos NC, Heathcote EJ, Chang TT, Kitis $\mathrm{G}$, Rizzetto $\mathrm{M}$ et al. Long-term therapy with adefovir dipivoxil for $\mathrm{HBeAg-negative} \mathrm{chronic} \mathrm{hepatitis} \mathrm{b} \mathrm{for} \mathrm{up} \mathrm{to} 5$ years. Gastroenterology 2006;131:1743-1751

8. Liaw YF, Sung JJ, Chow WC, Farrell G, Lee CZ, Yuen H et al. Lamivudine for patients with chronic hepatitis B and advanced liver disease. N Engl J Med 2004;351:1521-1531

9. Schiff ER, Lee SS, Chao YC, Kew Yoon S, Bessone F, Wu SS et al. Long-term treatment with entecavir induces reversal of advanced fibrosis or cirrhosis in patients with chronic hepatitis B. Clin Gastroenterol Hepatol 2011;9:274-276

10. Marcellin P, Gane E, Buti M, Afdhal N, Sievert W, Jacobson IM et al. Regression of cirrhosis during treatment with tenofovir disoproxil fumarate for chronic hepatitis B: a 5-year open-label follow-up study. Lancet 2013;381:468-475

11. Heathcote EJ, Marcellin P, Buti M, Gane E, De Man RA, Krastev $\mathrm{Z}$ et al. Three-year efficacy and safety of tenofovir disoproxil fumarate treatment for chronic hepatitis B. Gastroenterology 2011;140:132-143

12. Marcellin P, Heathcote EJ, Buti M, Gane E, de Man RA, Krastev $\mathrm{Z}$ et al. Tenofovir disoproxil fumarate versus adefovir dipivoxil for chronic hepatitis B. N Engl J Med 2008;359:2442-2455

13. Ishak K, Baptista A, Bianchi L, Callea F, De Groote J, Gudat F et al. Histological grading and staging of chronic hepatitis. J Hepatol 1995;22:696-699

14. El-Serag HB, Rudolph KL. Hepatocellular carcinoma: epidemiology and molecular carcinogenesis. Gastroenterology 2007;132: 2557-2576

15. Goldstein ST, Zhou F, Hadler SC, Bell BP, Mast EE, Margolis HS. A mathematical model to estimate global hepatitis B disease burden and vaccination impact. Int J Epidemiol 2005;34:13291339

16. Hyun JJ, Seo YS, Yoon E, Kim TH, Kim DJ, Kang HS et al. Comparison of the efficacies of lamivudine versus entecavir in patients with hepatitis B virus-related decompensated cirrhosis. Liver Int 2012;32:656-664

17. Chen YC, Chu CM, Yeh CT, Liaw YF. Natural course following the onset of cirrhosis in patients with chronic hepatitis B: a longterm follow-up study. Hepatol Int 2007;1:267-273

18. Seto WK, Liu K, Wong DK, Fung J, Huang FY, Hung IF et al. Patterns of hepatitis B surface antigen decline and hbv DNA suppression in Asian treatment-experienced chronic hepatitis B patients after three years of tenofovir treatment. J Hepatol 2013; 59:709-716

19. Marcellin P, Buti M, Krastev Z, de Man RA, Zeuzem S, Lou L et al. Kinetics of hepatitis B surface antigen loss in patients with HBeAg-positive chronic hepatitis B treated with tenofovir disoproxil fumarate. J Hepatol 2014;61(6):1228-1237. doi:10.1016/j. jhep.2014.07.019 